\title{
The social construction of indicators for evaluation: Internationalization of Funding Agencies
}

\author{
Emanuela Reale ${ }^{1, *}$, Annamaria Inzelt ${ }^{2}$, Benedetto Lepori ${ }^{3}$ and \\ Peter van den Besselaar ${ }^{4}$
}

\author{
${ }^{1}$ Institute for research on firms and growth-CERIS CNR, Rome, Italy, ${ }^{2}$ Co. IKU Innovation \\ Research - Financial Research Co., Budapest, Hungary, ${ }^{3}$ Università della Svizzera Italiana USI, \\ Lugano, Switzerland and ${ }^{4}$ Department of Organization Science \& Network Institute, VU University \\ Amsterdam, The Netherlands \\ *Corresponding author. Email: e.reale@ceris.cnr.it
}

\begin{abstract}
The article investigates the participatory co-development of suitable indicators for the assessment of internationalization of funding agencies (FAs). Our research questions are: How can we measure different functions and institutional characteristics using a participatory process? What and who do we measure (and assess), against what do we assess? Which of the stakeholders should/could use the indicators (ministerial principals to assess the agencies, agency leadership, agency staff, external evaluators) and for what purposes? In this way we intend to contribute to the literature on social construction of S\&T indicators, and to explore the representation of FAs' functions and activities for evaluation purposes. The results show how the process was designed and evolved, its strengths and weaknesses, and the effects generated as to the conceptualization for the indicators production. The work confirms the importance of indicators assessment forums for designing indicators, and how these arenas allow constituting a common language, enable the actors to discuss their representations, and favour collective learning.
\end{abstract}

Keywords: indicators; funding agencies; internationalization; evaluation; social construction.

\section{Introduction}

Internationalization and international standing are increasingly central issues for research organizations and for governmental R\&D policies. Many factors are behind the need to enhance recognition and reputation at a supranational level, the most important being competition for both human and financial resources, the globalization of the economy influencing also research and development in different institutional contexts, and finally new forms of knowledge dynamics within traditional and emerging new fields, increasingly taking place at the supranational level.

The article aims at investigating strengths and weaknesses of the participatory co-development of suitable indicators for the assessment of internationalization of funding agencies (FAs). Our research questions are: How can we measure different functions and institutional characteristics using a participatory process? What and who do we measure (and assess), against what do we assess? Which of the stakeholders should/could use the indicators (ministries assessing the agencies, agency leadership, agency staff, external evaluators) and for what purposes? In this way we intend to contribute to the literature on social construction of S\&T indicators, and to explore the representation of FAs' functions and activities for evaluation purposes.

We consider FAs as actors operating within different configurations based on national traditions. FAs can be 
agencies in the strict sense, or academies, or foundations. They can act exclusively as funding organization or can also play a role as research performer, thus assuming a more 'hybrid' nature. The common feature of all types of FAs discussed in this article is that they are in charge of public R\&D funding. They are implementers of public $\mathrm{R} \& \mathrm{D}$ policies on the basis of different delegation modes (Braun 2003).

The results are based on the work developed within the European Science Foundation (ESF) Member Organizations (MO) Forum on 'Indicators on Internationalization', which involved several FAs, namely the Academy of Finland-AKA, Finland; the Austrian Science Fund-FWF, Austria; the Research Foundation-Flanders-FWO, Belgium; the Danish National Research Foundation-DNRF, Denmark; Deutsche Forschungsgemeinschaft, DFG-Germany; Foundation for Polish Science, FPS Poland; the Research Council of Norway-RCN, Norway; Research Councils, RC-UK; the Swiss National Science Foundation-SNSF, Switzerland; and the Scientific and Technological Research Council-TUBITAK, Turkey.

\section{What we know from the literature}

We introduce in this section some concepts coming from the literature on the FAs characteristics and their relationship with other actors in the policy research space, as well as on the relevance of internationalization.

\subsection{Funding agencies characterization}

According to Braun (1998) the label 'funding agency' encompasses several types of organizations, which often are quasi-public entities 'financed by the State in order to define and execute a large part of the science policy'(p. $810)$. These organizations have been mostly investigated from the perspective of their role of intermediaries between government and the research performers under a principal-agent relationship with the government. They are policy actors that mediate between the policy level and the science community. The proximity to the government or to the science community shape their policy space, affecting also their objectives and strategies (Braun 2003; Caswill 2003; van der Meulen 2003). Other perspectives (Slipersaeter et al. 2007) consider them responsive institutions to other surrounding organizations, reacting and adapting to external pressures and limitations and trying to use their room of manoeuvre in order to mediate between external requirements and internal interests and needs (Slipersaeter et al. 2007).

The scope of the FAs' aims and policies had become much larger during the nineties due to the growing complexity and multilevel nature of the research policy arena (Lepori et al, 2007). Kuhlman (2001) highlighted the important role of strategic actors such as FAs in the governance of research and innovation policy at European level, and the possibility that such actors acquire new tasks in the internationalization of the European research, mediating between the national and the international policy level.

The relevance of funding organizations as actors of the research system is also related to the shift towards a managerial paradigm, and the related agencification process (Benner and Sandstrom 2000). In many European and non-European countries FAs underwent deep reform processes, affecting their functions and organization; in most of the cases the governments created a number of FAs pursuing different objectives and strategies and managing specific funding streams (OECD 2003). Thus, FAs have different missions, objectives, and strategies according to their positioning with respect to other political actors at the national and supranational levels.

In general, factors affecting changes within FAs are related to different issues such as the modifications in the configuration of the Government funding, the political will to enhance processes of marketization of the research performers (contract from industry, from competitive funding at national, supranational and local level), the setting of specific policy priorities (internationalization, innovation-oriented initiatives), the level of autonomy attributed to institutions and individuals, the changes in the modes of knowledge production with the emerging of new fields as well as the growing importance of multidisciplinary research, and the relevance and effectiveness of the instruments devoted to enhance accountability (evaluation).

It is also useful to recall that FAs are agents moving within specific interaction spaces of research systems, which correspond to different coordination modes in public funding: project-based, mixed, and vertically integrated modes (Lepori 2011). In the former mode, we can expect interaction spaces where different FAs coexist, and where the State control can go from the repartition of funds between agencies to the definition of the funding allocation criteria, agencies in all the cases retaining the control on the selection of the beneficiaries. The vertically integrated mode is dominated by 'umbrella organizations' (Skoie 1996) acting as basic layers for research funding on the basis of an extensive delegation of the state; the mixed mode might include project funding in combination with other modes, as funding attributes to consortia and networks (i.e., centres of excellence), which then regulate the repartition of resources between the partners, or the higher education core funding mode, where the main funding relationships are those between the state and the HEIs. The balancing between the different modes shapes the national configuration of the research system (Lepori 2011).

As far as evaluation is concerned, one can question if FAs can be identified in the set of funding schemes they promote and/or manage. Nedeva (2010) outlined that 
funding schemes and FAs differ as to the functionalities (the former being mono-functional, the latter being poly-functional), and as to the purposes (funding schemes are policy instruments devoted to pursue specific goals, while the FAs pursue the development of research capacity within the national $\mathrm{R} \& \mathrm{D}$ system). The differences affect also the organizational structure (flexible and temporary in the case of funding schemes, persistent and stable in the case of FAs) and impact on the specific goals of evaluation activities; when assessing internationalization of funding schemes, the expected results have to be addressed; in the case of FAs the focus of evaluation should compare what the organization is expected to do and what effectively does (Nedeva 2010). Accordingly, indicators for assessing internationalization of FAs go beyond the funding schemes they implement and look for evidences on the overall effort of the organization towards internationalization, with respect to mission, objectives and strategies.

\subsection{Internationalization}

Internationalization is a central characteristic of research activities, affecting all the scientific disciplines with different rate and pace.

In the last decades, internationalization emerged as a policy goal in itself and as an instrument to support other goals (Boekholt et al. 2009). It affects all institutional levels (policies, governance and instruments, intermediaries, research performers and groups), producing different consequences; strategies towards internationalization emerged, following different motivations and rationales according to the national configuration and the political will. Internationalization of the research at system, organization, group or individual level, is driven by the globalization of economies, the increased competition for good researchers and research funds, and the need to improve reputation and visibility at the knowledge frontier (Veugelers et al. 2005). More specifically, the literature (Georghiou 1998; CREST 2008, Boekholt et al., 2009) highlighted several rationales affecting public policies toward internationalization, which can be summarized in the following items: (1) strengthening research excellence and innovation performance through enlarging the set of actors for collaboration and/or for getting complementary expertise (critical mass, complementarities); (2) increasing the attractiveness of the $R \& D$ system in order to improve the capability to compete in the global market (enlarging the innovation network); (3) responding to global problems, positioning the country in the large community fostering common ideas and values (global coverage).

Also the meaning of internationalization evolved: from internationalization of researchers and research groups, to internationalization as embedment of institutions and individuals in international networks, capability to act at the frontier of the research, to attract foreigners (researchers, clients), and to localize research activities abroad (researchers and units). Gornitzka et al. (2003) distinguished between different concepts related to internationalization, and suggested the existence of different patterns that can be labelled as 'traditional' or 'emerging'. In traditional patterns the autonomous initiatives of individuals and of corporate research institutions are more important than government policy initiatives. Emerging patterns are characterized as 'institutionalized, market-controlled, technology-dominated, rule-driven process', with cooperation and competition at the different government levels as driving factors, and a strong influence of supranational institutions.

From 2000s, policies developed at European level contributed to diffusing internationalization as a policy objective to be achieved by national governments. (Trondal 2002). The European Framework Programmes, the Lisbon strategy, and the concept of an European Research AreaERA (David and Metcalfe 2007; European Commission 2001; ERAWATCH 2007, 2009) generated different effects, such as driving national government R\&D allocation, the establishment specific schemes of project funding and incentives, changing the political rhetoric in terms of rationales and justification for public investment in $\mathrm{R} \& \mathrm{D}$, but also modified the awareness of research organizations of the relevance of the non-national level of governance.

Edler (2010) highlights a conceptual differentiation between collaboration, coordination, and integration, the former referring to joint activity or project, the second being a process through which an harmonization of different activities (policy instruments, research activities) is pursued in order to better synergies and interactions. Integration instead is a complex notion, which refers to the process of construction of relationships between different European research actors, decision makers, funders and performers, then becoming stable and institutionalized, and producing effects, which lead to the establishment of a new entity, deriving from the composition/integration of some components into the new one (Luukkonen and Nedeva 2010). Integration at the level of research performer takes place through joining of research capacities, while at the level of research policy means the creation of a common instrument (e.g., a research programme), merging different functionalities (e.g., design of the instrument, organization and management, selection and evaluation, Edler 2010).

Although internationalization is becoming a key issue on the political agenda, we still have little empirical evidences, and indicators still need dedicated work. Edler and Flanagan (2011) stressed the importance of developing indicators on internationalization of science policy, able to support the drivers and the interests with concrete evidences. 


\section{The social construction of indicators}

Designing new indicators always requires a thorough understanding of the policy context and of the main issues and questions at stake; this is where the interaction between indicators specialists on the one side, specialists in research policy and policy actors on the other side is extremely fruitful. Since indicators are social constructs, their relevance and acceptance can be enhanced if the design process involves the interested parties (Barré 2004). Moreover, when indicators serve the evaluation process, they need to be designed starting from the evaluation objectives and then valuated and interpreted keeping in mind their limitations in representing the intended phenomenon or effect (Barré 2004).

Adopting a participatory process allows mediating between the views of the different actors involved, thus reinforcing the reliability (accuracy and coherence of the indicators), the relevance for decision-making or managing processes, and the awareness of the strengths and weaknesses of the indicators. Participatory processes are also expected favouring the possibility of indicators to be used as instruments for collective learning and discussion, leading to sharing interpretation of the underlying reality they are devoted to represent (Barré 2010).

While the scholarly community provides the conceptual basis for developing indicators, based on a representation of the reality that come from theory and empirical controls. But this representation can be different from the perception that FAs have their role and their positioning within the R\&D system at national and supranational level, and the discrepancy between these perspectives impact on the selection and the use of indicators.

The production of indicators relies on two main processes (Probst et al. 2011): in the experimental design phase, indicators are conceived, a methodology for their production is developed and testing is made in order to prove feasibility and relevance; in the capitalization phase, a systematic and long-term production of indicators based on a stabilized methodology is established. While capitalization is usually a task of statistical agencies, the academic context is more suitable to experimental development, due to the need of performing experiments based on trials and error before stabilizing the methodology.

Although literature on participatory policy-making is very rich, only few works deal with participatory indicator development on science and technology (Godin 2005). This latter may find in the practice of some organisations such as OECD working group of National Experts on Science and Technology Indicators (NESTI).

In this project, the methodological framework for indicators development was developed in a participatory process, which involved on the one hand experts in the field of indicators, on the other hand the FAs that volunteered for selecting relevant indicators aimed at assessing internationalization. As the structure of the ESF MO Forum is concerned, ESF was the sponsor of the initiative, which was launched from a request and interest of the FAs involved.

The process was a typical user-producer-designer interactive approach, where the actors, FAs and indicator specialists, with different roles and expertises, worked together to build appropriate, robust, and feasible indicators. The experts proposed a conceptual framework and a methodology, and led the phases of testing the selected indicators; FAs discussed the expert's proposals and the results, on the base of their understanding and interests in assessing internationalization. Moreover, FAs are not only potential users of indicators but data providers too, since all of them hold administrative records for different purposes. Some of them have developed databanks too. Both are a key source for producing indicators. A mediation of the different views was made through debating, keeping reference on the literature on the one hand, and on the FAs needs on the other hand.

\section{Methodology}

\subsection{The need of indicators on internationalization}

The first step was to create an agreement on why we need indicators for internationalization. The experts suggested to consider FAs as organizations influencing the research system by contributing to determine 'what will be investigated and by whom' (Braun 1998: 810), as well as the way in which the research can be done. The former role is linked to the provision of funding resources, while the latter occurs on the basis of rules, regulation, criteria setting, which impact on reputational control (Benner and Sandstrom 2000). Indicators on the internationalization of FAs can supply useful information for: (1) improving the understanding of the complementarities between existing instruments, and the specific sphere of influence with respect to other FAs operating at national level; (2) highlighting the weaknesses of the FAs' funding portfolio, and the capability to answer to the requests from the science community; and (3) clarifying the linkages with their governance and organizational settings, putting into evidence how the internationalization at policy level influences the FAs, as well as the roles they play in different countries. Being an actor at international level can help to enhance the quality of the national funding system; a strong international research position might be crucial for exerting influence on supranational research policies. These two advantages are perceived in different ways, and their importance is weighted on the basis of different rationales, according to the mode of coordination adopted by the national governments and the agencies themselves. 


\subsection{Evaluation of FAs internationalization}

Since indicators for evaluation purposes must be customized, identifying the main aim of assessing internationalization is an important task. Indicators can be suited for traditional (ex post, interim) 'assessment' for informing policy makers and stakeholders, or for strategic development of the agency, or for improving the understanding of global developments.

Moreover, when FAs considered the assessment perspective, different purposes for indicators on internationalization were highlighted, as measures contributing to: (1) improve the conditions under which target research groups can perform research in a globalizing system; (2) measure the output quality, the efficiency of knowledge production and the like of the research system; (3) improve the conditions under which the staff of the agency can work (e.g., learning through internationalization, internationalizing their own activities); and (4) allow ministerial principals and other interested stakeholders to assess the performance of the agencies in terms of taking advantage of the international dimension across its functions and its stated goal internationalization.

FAs considered the assessment of their accountability toward stakeholders, the improvement of their strategic capabilities as the most useful aim. Two key questions identified were: why and to what extent are we investing in collaborative international research? What are the outcomes of investing in international activities?

FAs recognized, discussing the respective missions and tasks, that for the aim of the exercise, indicators must be related to the agencies as organizations, not to the programmes they manage, thus they are expected to refer to several functions they perform, in order to promote the internationalization of the research system. In this context programme related data are building blocks to indicators on FAs. The FAs' answers outlined that the reasons for investing in internationalization are related to competition, globalization, and the emergence of new dynamics in research, which pushed toward going beyond the national arena. Their mission is expanding the framework for Europeanization as well as internationalization of research performing organizations. The main expected outcome to be detected through indicators are: (1) the growing relevance of funding schemes pursuing internationalization in the funding portfolio of the agencies; (2) an investment of the funding agencies for maintaining an international standing in the functions performed; (3) the internationalization of the beneficiaries, thus the research performers funded. As to the purpose of indicators, the interests were mainly related to building strategies and reframing the research-funding portfolio of investment; also motivations linked to accountability toward the Ministries emerged, an achievement that is considered intrinsically linked to the improvement of the FAs strategic capability.

\subsection{The conceptual framework for indicators}

Indicators as social constructs are representing the interests of the diverse actors at stake: in our case the FAs' have different interests as they are organizations funding targeted beneficiaries, strategic actors involved in the multilayered research policy space, and at the same time customers of the measures produced. One approach for dealing with internationalization can be to build a classification of the Agencies based on their characteristics. In this case, belonging to one or another category can depend from some important characteristics related to internationalization (Bryant 2000). A different approach is not to relying on objective and clear-cut criteria to classifying FAs, because many uncertain and borderline cases would emerge, and the criteria for classification can be subject to disagreement, related to diverging assumptions on which the core characteristics of FAs internationalization are. A solution is to conceptualizing the FAs as organizations that manage several functions linked to their funding activities, and trying to design proper indicators (measures) for capturing the level of internationalization of each function performed.

Assuming FAs organizations contributing to shape the research system, impacting what and how the system must evolve, and who should act as main beneficiary, 'structuring research performance and the institutional norms of academic research' (Benner and Sandstrom 2000), we can identify the main general functions of the agencies as related to: (1) the designing of the funding instruments, shaping the goals and the content of the expected research activities; (2) the selection procedures, thus the set of rules for submitting the proposals, and for assessing the targeted beneficiaries; (3) the funding decisions, supplying a significant amount of resources allowing the pursuing of the research objectives; and (4) the management of the contract relationships with the beneficiaries, and the internal governance.

The mentioned functions are related to the objectives FAs want to pursue through funding actions, which can be summarized into four large macro goals: (1) sustaining excellence and innovation of knowledge production; (2) favouring the knowledge circulation, within and between sectors and organizations, nation state and supranational level, tacit and codified knowledge; (3) incentive the collaboration between researchers and the capability of networking among research organization; and (4) promoting an adequate level of funding to transnational research activities.

If we want to assess FAs internationalization, we need measures (indicators) aimed at capturing the extent to which the functions and the related funding actions developed by the agencies are internationalized. This can be represented through identifying what do we assess for each function and the purpose of the indicator (what do we measure, see Prospect 1). 
Prospect 1. Framework for assessing internationalization

\begin{tabular}{|c|c|c|}
\hline Functions & What do we assess & Purpose of the indicator (what do we measure) \\
\hline Funding decision & Level of funding for objectives related to internationalization & $\begin{array}{l}\text { Resource flow to programmes funding trans-national research } \\
\text { activities }\end{array}$ \\
\hline $\begin{array}{l}\text { Designing funding } \\
\text { instruments }\end{array}$ & $\begin{array}{l}\text { Presence of a portfolio of funding instruments for pursuing } \\
\text { excellence, innovation, and the circulation of tacit and } \\
\text { codified knowledge }\end{array}$ & $\begin{array}{l}\text { Knowledge production and circulation through mobility of } \\
\text { researchers (senior and junior), workshops and conferences, } \\
\text { international research } \\
\text { Collaborations, funding researchers working abroad }\end{array}$ \\
\hline Selection procedures & $\begin{array}{l}\text { Capability to choose the best researchers for successfully } \\
\text { perform at international level }\end{array}$ & $\begin{array}{l}\text { Knowledge production of the selected beneficiaries } \\
\text { Involvement of non-national peers in the selection committees }\end{array}$ \\
\hline $\begin{array}{l}\text { Management and } \\
\text { governance }\end{array}$ & $\begin{array}{l}\text { Management aimed at improving trans-national research } \\
\text { activities } \\
\text { Capability to influence and monitoring the policy making and } \\
\text { research activities at international level }\end{array}$ & $\begin{array}{l}\text { International programming (joint design, selection, } \\
\text { management) } \\
\text { Hiring from abroad, and units located abroad }\end{array}$ \\
\hline
\end{tabular}

As far as the participatory process is able to involve a large part of the actor's constellation, all the mentioned issues can be taken into account; as far as the process involve a more reduced type of actors, the interests the indicators would serve will be more circumscribed. The work presented in this article derives from the interactions between experts and FAs, not including other users such as ministries or stakeholders; thus, the participatory process reflects a social construction where the interests represented are circumscribed to a specific group of users, which are also the indicators producers. This means that the robustness of the indicators as 'instruments for collective learning leading to shared interpretation' (Barré 2004, 2010 ) is to some extent limited. The social construction did not involved representatives of the statistical offices, since it was conceived as an exploratory activity aimed at identifying shared indicators for assessing FAs internationalization; thus, the results pursued were more direct to conceptualization and methodology than to empirical findings.

\subsection{Toward designing indicators for assessing internationalization}

The FAs involved in the ESF MO Forum compiled a list of possible indicators of internationalization by different functions performed. The Forum launched a mapping exercise in order to monitor the needs of the agencies, to identify the potential data sources to indicators, check the actual or near future availability of data, and to collect the available data and indicators deployed by FAs. The data collection was based on a questionnaire focusing on three key dimensions: funding of programmes, knowledge circulation, and knowledge production. Some traditional indicators are useful to respond to the questions on internationalization; a dedicated workshop highlighted the needs for a sampling method and data collection. Additionally, functions performed were related to FAs rationales, those recognized as the most relevant for internationalization, since they are strictly related to the intentions implemented through the national public policies: gaining a critical mass, address complementarities, gaining a more global coverage in some research area/theme, enlarging the innovation network.

Based on the conceptual framework and on the results of the mapping exercise, a matrix between the dimensions of internationalization (functions performed through actions) and the four types of rationales (intentions for actions) has been developed in order to identify a limited set of indicators for assessing internationalization and supporting strategic choices of FAs and accountability, tough hard facts proven by acceptable measures/proxies (Table 1).

A minimum set of indicators on the internationalization of FAs functions has been outlined, and then tested by the participating agencies. The indicators have been discussed as to:

- Validity (representativeness of internationalization of FAs functions),

- Relevance (capability to measure what is effectively important for the users involved),

- Reliability (defined as 'accuracy of the computation of the indicator and coherence between what is measured and what is supposed to be measured', Barré 2004, p.124),

- Feasibility (availability of data and time for producing indicators).

Other aspects were not deeply discussed, although relevant, due to the explorative character of the participatory process, namely independence (developing indicators not affected by bias coming from external influences), and transparency (rules for the general recognition of the process to design the indicators and the data used). Also the comparability of indicators produced by the different actors in different countries was left as one element to be discussed in a more mature phase of indicator production. 
Table 1. Internationalization of Funding Agencies

\begin{tabular}{|c|c|c|c|c|c|}
\hline Dimensions Rationales & Resources flow & $\begin{array}{l}\text { Funding knowledge } \\
\text { production }\end{array}$ & $\begin{array}{l}\text { Funding knowledge } \\
\text { Circulation }\end{array}$ & $\begin{array}{l}\text { Funding collaboration } \\
\text { and networking }\end{array}$ & $\begin{array}{l}\text { Governance and } \\
\text { processes }\end{array}$ \\
\hline Critical mass & $\begin{array}{l}\text { Joint Research } \\
\text { Programmes (JRP) }\end{array}$ & $\begin{array}{l}\text { Co-authored } \\
\text { publications with } \\
\text { European partners }\end{array}$ & Mobility of researchers & $\begin{array}{l}\text { Shared infrastructures } \\
\text { (LSF) Joint } \\
\text { programmes }\end{array}$ & $\begin{array}{l}\text { International } \\
\text { programming } \\
\text { (design, selection, } \\
\text { management) }\end{array}$ \\
\hline Complementarities & $\begin{array}{l}\text { Joint Research } \\
\text { Programmes (JRP) }\end{array}$ & European co-patenting & $\begin{array}{l}\text { Workshops and } \\
\text { conferences }\end{array}$ & $\begin{array}{l}\text { Shared infrastructures } \\
\text { (LSF) Joint } \\
\text { programmes }\end{array}$ & Units located abroad \\
\hline Global coverage & $\begin{array}{l}\text { International joint } \\
\text { programmes }\end{array}$ & $\begin{array}{l}\text { Co-authored } \\
\text { publications with } \\
\text { international partners }\end{array}$ & $\begin{array}{l}\text { Recruitment from } \\
\text { abroad }\end{array}$ & Bilateral agreements & $\begin{array}{l}\text { Foreign reviewers and } \\
\text { panellists }\end{array}$ \\
\hline $\begin{array}{l}\text { Enlarging innovation } \\
\text { networks }\end{array}$ & $\begin{array}{l}\text { Openness of the } \\
\text { programmes }\end{array}$ & $\begin{array}{l}\text { International } \\
\text { co-patenting }\end{array}$ & Mobility of $\mathrm{PhD}$ & $\begin{array}{l}\text { Foreign reviewers and } \\
\text { panellists }\end{array}$ & $\begin{array}{l}\text { Recruitment from } \\
\text { abroad }\end{array}$ \\
\hline
\end{tabular}

Some indicators were considered not useful, due to the low relevance (e.g., units located abroad), and reliability (e.g., workshops and conferences); in some cases indicators were abandoned because of availability constraints (e.g., recruitment from abroad). ${ }^{1}$

\section{Indicators for assessing the internationalization of the Funding Agencies}

In this paragraph, we present and discuss the basic set of indicators that emerged during the participatory process as key measures for the evaluation of the internationalization of the FAs. The first section starts with proposing a profile of the FAs involved in the ESF MO Forum, in order to understand how different the sample of the participating agencies is. The second section presents the indicators selected; in the last section a discussion is developed questioning the robustness of the indicators in terms of validity (do they address the issue of internationalization?), relevance (do they measure important issues?), availability (can the indicators be produced with an acceptable effort?), and reliability (can they produce non-ambiguous measures?).

\subsection{Inside the sample: a profile of the participating FAs}

Building profiles of FAs is a complicated affair, given the different entities at place within Europe. One very general distinction proposed in the literature (Braun 1998) identifies three ideal types of FAs, namely the science-based FAs, the strategic FAs, and the political FAs. The former are devoted to support the interest of the scientific community, with no selection of some disciplines instead of others; the second are devoted to promote research in a particular sector or area (e.g., health or agriculture, or environment); the latter are more rare cases of organizations devoted to serve the interest of a Ministry. We can also note that FAs can be distinct on the basis of how close they are to the implementation of government policies, or, in other words, if they are intermediaries playing a central role in the governance of the R\&D system of the country, or are more independent agencies, with a lowest responsiveness to the policy makers.

Based on available source of information (ERAWATCH 2007), some commonalities of the agencies participating to the exploratory initiative of the ESF MO Forum can be outlined, which are relevant for understanding the results of the participatory process.

5.1.1 Science-based FAs. Examples: SNSF in Switzerland, FWF in Austria, AKA in Finland, FPS in Poland, and FWO in Belgium, are all agencies designing, implementing and managing the major sources for bottom-up responsive mode funding of basic, curiosity-driven research, thus supporting research projects and programmes on the basis of their quality and excellence in different research areas. RCN in Norway can be also included, although as research council, its role is broader that the other agencies in terms of functionalities performed and responsiveness toward the government policies. The same holds true for the case of DFG in Germany.

The agencies are actors playing a leading role for project funding of basic research of universities and academic-like organizations. They are intermediary layers between the government and the performers, always characterized by substantial autonomy, in terms of room of manoeuvre for setting their strategies and design appropriate schemes for sustaining the national research effort. The characteristics of the overall government of the research system, the policy space they can have between the ministry and the performers, and the coordination modes of public funding 
existing at national level influence the way in which the agencies interpreted the issue of internationalization.

DNRF is similar to the mentioned agencies, although it is a separate foundation for basic research, independent from the government; it was settled by a government act, and it is the Denmark government that provides the funding resources as well. The difference is that it does not act as an agency but rather as a foundation, thus it is a separate body from the other two national intermediary organizations, the Danish Councils for independent research and the Danish Councils for strategic research, respectively devoted to support curiosity-driven research and targeted research based on policy initiatives. The core mission is to fund excellent high international standing research and researchers, and one key instrument has been the centre of excellence.

5.1.2 Strategic FAs. Example: RCs in UK, operating in different scientific fields, whose aim is to pursue internationalization become more evident from 2007 with the setting of an explicit strategy overarching all seven research councils, differentiating the approaches between countries (within Europe, outside Europe; industrialized countries, emerging economies), and developing several dedicated instruments for enhance international cooperation of scientists and research groups.

5.1.3 Political, multi-task FAs. Example: TUBITAK is a different and particular case of a multi-task hybrid organization, since it is devoted to support innovation, academic and industrial $\mathrm{R} \& \mathrm{D}$, through thematic programmes, to support PhD students with scholarships, to be a publisher of scientific journals and of popular magazines for the diffusion of the scientific culture; it also is a research performer through a range of different research centres and institutes in all the disciplines and scientific areas. This case is related to a vertically integrated mode of public funding, with the agency playing a broader role than funding, acting in close relationship with the Ministry of Research.

Summing up, the participatory process involved very diverse type of actors as to the interests, mission, strategies, and positioning in the national research system; consequently different perspectives on internationalization are supposed to affect the level of each function assessed through indicators. The FAs involved were most of the time working in small and medium size countries, with relatively small scientific community by fields. They are funding basic science and their main clients are in public research.

\subsection{The indicators selected}

The indicators selected as valid and relevant for assessing the internationalization of the FAs' functions are shown in
Table 2. The measures used and the breakdown, have been agreed in a common workshop; there was a general consensus on the need to focus on nine indicators, along the dimensions outlined in the previous section.

The test of selected indicators shows:

- Internal databases and reporting activities are crucial data sources, thus confirming the richness of micro data for building comparable indicators;

- Information on mobility presents some constraints from a conceptual point of view (e.g., what is a mobile researcher? How to deal with the problem of nationality versus place of residence? Inzelt 2010), and problems related to the data collection, since funding for mobility is a component of different funding schemes, which include other objectives;

- The participation of foreigners' reviewers, and panellists for the ex ante selection of beneficiaries was judged a valid and relevant indicator for the assessment of internationalization. The presence of external experts from the international arena in the panel, and the involvement as reviewer, are signals of agencies' search for visibility and objectivity of the evaluation processes;

- Output indicators (international co-publication and co-patenting) present the well-known problems of attribution and time lag. Patent-based indicators have been considered not applicable to agencies funding basic research. However, in the case of FAs with a broader funding portfolio, less concentrated on basic researchsuch as research councils - patents might rise in importance as indicators of internationalization.

Table 3 summarizes how valid FAs consider indicators, and the relevance they can have for different type of users (policy makers, stakeholders, and FAs themselves for strategic planning and priority setting). The indicators were divided in three categories according to their status: (1) pilot indicators (tested either with spot-data or time series); (2) indicators under development (some clarification needed to develop them, including definition, classification, and breakdown problems); and (3) blue sky indicators (no agreement on how to define them, further research is needed).

\subsection{Discussion}

Summarizing the outcome of the process, we can outline some interesting results. A consensus between experts and FAs, and among the FAs, on how measures for the evaluation of internationalization could be constructed:

- FAs can be investigated with indicators aimed at analysing the different characteristics of the funding functions performed, in our case internationalization and the international perspective they pursue. Moreover, the approach by function can provide a base for further development of indicators for FAs 
Table 2. Indicators selected

\begin{tabular}{|c|c|c|c|}
\hline Indicator name & Dimension & Unit & Feasibility and sources \\
\hline $\begin{array}{l}\text { Budget for Joint Research } \\
\text { Programmes }\end{array}$ & Resource flow & $\begin{array}{l}\text { Budget and share of total direct } \\
\text { research funding budget }\end{array}$ & Internal data base on budget allocation \\
\hline Co-funded research output & $\begin{array}{l}\text { Resource flow/funding } \\
\text { knowledge production }\end{array}$ & $\begin{array}{l}\text { Share of funded papers which are } \\
\text { internationally co-funded }\end{array}$ & $\begin{array}{l}\text { Not all joint funding fits the category } \\
\text { International databases of publications } \\
\text { using the field acknowledging to } \\
\text { funders (WoS) }\end{array}$ \\
\hline \multirow[t]{2}{*}{ Budget spent abroad } & Resource flow & $\begin{array}{l}\text { Budget and share of total direct } \\
\text { research funding budget }\end{array}$ & Internal data base on budget allocation \\
\hline & & & $\begin{array}{l}\text { Difficult to identify money effectively } \\
\text { spent abroad }\end{array}$ \\
\hline \multirow[t]{2}{*}{ Openness of programmes } & $\begin{array}{l}\text { Resource flow/funding } \\
\text { knowledge production }\end{array}$ & Number of non-national applicants & Internal database \\
\hline & & $\begin{array}{l}\text { Share of funded papers with no } \\
\text { national authors }\end{array}$ & $\begin{array}{l}\text { International databases of publications } \\
\text { using the field acknowledging to } \\
\text { funders (WoS) }\end{array}$ \\
\hline International co-authored papers & $\begin{array}{l}\text { Funding knowledge } \\
\text { production }\end{array}$ & $\begin{array}{l}\text { Share of funded papers with } \\
\text { international co-authors / share of } \\
\text { national output with international } \\
\text { co-authors }\end{array}$ & $\begin{array}{l}\text { International database of publications } \\
\text { using the field acknowledging to } \\
\text { funders (WoS) }\end{array}$ \\
\hline International co-patenting & $\begin{array}{l}\text { Funding knowledge } \\
\text { production }\end{array}$ & $\begin{array}{l}\text { Share of funded patents in total } \\
\text { national patent output }\end{array}$ & International database \\
\hline $\begin{array}{l}\text { Budget for attracting researchers } \\
\text { from abroad }\end{array}$ & $\begin{array}{l}\text { Funding knowledge } \\
\text { circulation }\end{array}$ & $\begin{array}{l}\text { Budget and share of total direct } \\
\text { research funding budget }\end{array}$ & $\begin{array}{l}\text { Difficult to be analysed and collected } \\
\text { Internal data base on budget allocation }\end{array}$ \\
\hline International mobility & $\begin{array}{l}\text { Funding knowledge } \\
\text { circulation }\end{array}$ & $\begin{array}{l}\text { Number of researchers (head count) } \\
\text { whose mobility has been funded } \\
\text { (Incoming and outgoing) }\end{array}$ & $\begin{array}{l}\text { Annual report } \\
\text { Internal database, annual report. } \\
\text { Available but uncertain, depends on } \\
\text { quality of reports from beneficiaries } \\
\text { uses }\end{array}$ \\
\hline Evaluation & Governance and processes & $\begin{array}{l}\text { Share of total number of evaluators } \\
\text { coming from abroad }\end{array}$ & Internal database. Annual report. \\
\hline
\end{tabular}

evaluation purposes, beyond the ones on internationalization;

- Indicators can be related to different rationales of FAs. The matrix of rationales and the dimensions of internationalization provided a guide to the selection of indicators for evaluation purposes, which may serve different users beyond the FAs.

The debate outlined that funding agencies are actors, which perceive themselves differently; their role and positioning is evolving toward becoming strategic institutions, more autonomous from the political steering, a process that is supposed to affect the governance of the national S\&T systems. Also the FAs' role is related to the different profiles of the agencies, to their mission and tasks, as well as to their relationships in the actors' constellation. The convergence of so different organizations toward considering some indicators relevant can improve the understanding of the functions they perform.

There was a broad agreement that indicators relating to resource flow are all measuring key features of internationalization. The possibility to disaggregate the data by type of programmes, and the availability of information on some features of the programmes (main objective, type of delegation, rules for selection and targeted beneficiaries) would supply robust evidences on patterns of internationalization of the FAs strategies. For budget spent abroad some difficulties emerged; as an example AKA noticed that 'it can indicates two separate things: (1) what the funding decision was aimed at; and (2) the actual use of funding. Budget for (1) is available, but not for (2)'.

A further remark is about the role that bibliometric indicators can play to help FAs in designing funding instruments and in developing selection processes, which promote the internationalization of the knowledge production. Using the acknowledgements of funders, public and private, national and international, listed in the papers, it is possible to look at funding international co-authored papers as well as at international co-funding of international co-authored papers. Also non-internationally authored papers funded from abroad can be analysed through FAs acknowledgements. A preliminary exploration of the mentioned possibilities confirmed the potential of these indicators, as well as the need to overcome problems of cleaning and disambiguation to be applied on a large scale (van den Besselaar et al. 2012). 
Table 3. Use, users, and status of the selected indicators

\begin{tabular}{|c|c|c|c|}
\hline Name of the Indicator & Use & Users & Status \\
\hline \multirow{3}{*}{$\begin{array}{l}\text { Budget for Joint Research } \\
\text { Programmes (JRP) }\end{array}$} & Intensity of funding for collaboration & Policy makers & \multirow{3}{*}{ Pilot indicator } \\
\hline & European integration as to joint funding & Stakeholders & \\
\hline & International collaboration, mutual learning & FAs & \\
\hline Co-funded research output & $\begin{array}{l}\text { Knowledge produced on the basis of funding coming from } \\
\text { FAs of different countries }\end{array}$ & FAs & Blue sky \\
\hline \multirow[t]{3}{*}{ Budget spending abroad } & Money follows researchers & Policy makers & \multirow[t]{3}{*}{ Blue sky } \\
\hline & Extent of cross-border funding schemes & FAs & \\
\hline & Enrich international scope of research activities & & \\
\hline \multirow[t]{2}{*}{ Openness of the programmes } & Money follows researchers & Policy makers & \multirow[t]{2}{*}{ Under development } \\
\hline & Effective openness of the research funding & $\begin{array}{l}\text { Stakeholders } \\
\text { FAs }\end{array}$ & \\
\hline \multirow[t]{2}{*}{ International co-authored papers } & $\begin{array}{l}\text { Monitoring output from international collaboration and } \\
\text { international linkages }\end{array}$ & Policy makers & \multirow[t]{2}{*}{ Under development } \\
\hline & Effectiveness of international collaboration & FAs & \\
\hline \multirow[t]{2}{*}{ International co-patenting } & $\begin{array}{l}\text { Monitoring output from international collaboration and } \\
\text { international linkages }\end{array}$ & Policy makers & \multirow[t]{2}{*}{ Under developmen } \\
\hline & Effectiveness of international collaboration & FAs & \\
\hline \multirow{2}{*}{$\begin{array}{l}\text { Budget for attracting researchers } \\
\text { from abroad }\end{array}$} & Brain circulation and brain gain & Policy makers & \multirow[t]{2}{*}{ Pilot indicator } \\
\hline & Analysis of funding for mobility & FAs & \\
\hline \multirow[t]{3}{*}{ International mobility } & $\begin{array}{l}\text { Internationalization of disciplines and integration into inter- } \\
\text { national science }\end{array}$ & Policy makers & \multirow[t]{3}{*}{ Under development } \\
\hline & $\begin{array}{l}\text { Supporting career development, international experience, } \\
\text { mutual learning }\end{array}$ & Stakeholders & \\
\hline & Integration into international science & FAs & \\
\hline \multirow[t]{3}{*}{ Evaluation } & $\begin{array}{l}\text { Internationalization of peer review to enhance 'objectivity' in } \\
\text { selection processes }\end{array}$ & Policy makers & \multirow[t]{3}{*}{ Pilot indicator } \\
\hline & $\begin{array}{l}\text { Benefits from experiences and perception of foreign panellists } \\
\text { and reviewers }\end{array}$ & Stakeholders & \\
\hline & & FAs & \\
\hline
\end{tabular}

The consensus reached on foreign reviewers and panellists reveal the potential of indicators investigating internationalization of evaluation processes. In the case of this indicator the size of the country matters: in small countries non-national reviewers and panellists are needed because of lack of expertise or small size of the research sector. Size sensitivity of these indicators has to be taken into account in international comparison.

\section{Conclusions}

We can now outline some general lessons on the construction of indicators for assessing funding agencies.

The participatory process reveals its strengths and weaknesses, the former being the capability to build indicators based on effective understanding of the needs of the actors involved and of the use the indicator can have. A thorough check of the indicators validity, feasibility and meaning, as well as the development of a learning process involving all the participants were also guaranteed; the weaknesses being the need for time, and for deep interactions between the actors, including physical meetings, in order to gain a consensus on a list of relevant measures. Further non-obvious achievement was the convergence of the different cognitive frames of the organizations involved, with a common re-definition of the background of the selected indicators, distinguishing between what they want to know, and what they really can know.

The process did not involve statistical offices, stakeholders or Ministries, as it was an explorative work developed by the Member Funding Agencies participating to the ESF Forum, which decided to develop and to test few indicators, to be used by them all for the evaluation of the internationalization, the strategic aim being the development of a common understanding and measuring of a key feature. The results are more linked to conceptualization and empirical tests (mapping and checking on data availability), than on pilot developing of indicators.

What emerged is that the social construction of indicators needs some requisites, whose presence is relevant for succeeding: technical expertise, strategic vision, awareness of the assessment needs and use, discussion for consensus building, cognitive convergence around common representations. Following a step-by-step path is crucial, because it gives time to the actors involved converging around common definitions and conceptualization. Defining 
precise functions of the participants is also important: the role of the experts as providers of technical and academic knowledge; the role of FAs, in our case acting as both producers and users of indicators, for understanding the evaluation needs, the objective of indicators, and the reliability of the conceptualization. The agreement of looking at FAs as set of functions performed for pursuing mission and targeted objectives, and deploying internationalization through indicators related to the functions themselves were the most laborious results, as to the struggle generated and different opinions and ideas in place. Moreover, concentrating on a small set of indicators, looking at how mature they are to be produced in a regular and standardized way, are two further important requisites.

The debate also let different perspectives emerge between the FAs about the assessment of internationalization, which affected the indicators selection. Internationalization is a broad word whose content is difficult to grasp; in most cases of our sample it is Europeanization the real target FAs want to achieve, the international arena largely coinciding with the EU27 perimeter (European Commission 2001). Internationalization can be driven by strategies towards gaining sectoral complementarities and critical mass in open research systems like Switzerland, Norway, and Denmark, but also in countries that pursue the access in Europe, such as the case of Turkey. Other countries stressed the needs of monitoring the international landscape, benchmarking and networking, with a more prudent behaviour toward the openness of the system. In all the cases, internationalization has a strong content linked to visibility and reputation of the research system, and it is influenced by the national funding coordination modes.

These remarks can be useful in order to deepen what in reality internationalization is, beyond the political discourses and rhetoric. For instance, the mapping exercise on indicators showed that FAs interpret collaborations as behaviours, to be sustained and promoted because they are characterizing the knowledge production of science communities also in arenas such as social sciences and humanities, traditionally more linked to national-based network than other disciplines.

The same does not apply for coordination and integration. FAs perceived coordination as a precise policy objective whose importance is growing, but national configurations strongly affect the way in which they design the strategies and implement them. As an example, science-based FAs in small countries, with a mixed funding configuration and a relevant investment on R\&D, explicitly highlighted the existence of pressures for enlarging the networking in order to overcome scale and scope constraints, a factor explaining the pro-active behaviour toward internationalization. Indicators also provide a good support for discussing differences between countries and actors. Strategic FAs like RCs revealed more precise designs toward coordination: the RCUK for instance, declared to consider

the direction and ambition of the organisations in terms of strategy and policy, and these will be informed by relevant evaluation activities. Input will be received from scientists and funded institutions as well as from policy papers drafted in Europe and globally. Where there is value in conducting research across national boundaries, RCUK aims to ensure that opportunities are taken to engage appropriate partners. A flexible portfolio of approaches is operated by members of RCUK in recognition of the needs of the different research communities and the specific requirements of individual partner countries.

Summing up, this work confirms the importance of the assessment forums for designing indicators, and how these arenas can enhance the two key properties of indicators (Barré 2010): constructing a common language, and enabling the actors to discuss their representations, thus favouring collective learning processes. In our experience, the social construction of indicators supported a better understanding of internationalization of FAs functions and internal governance, how they interpret the role of actors dealing with national and supranational arenas, enhancing collaborations with non-national funding agencies, and how much the FAs' efforts for internationalization are coordinated with national policies for international collaborations.

\section{Acknowledgements}

The article is based on the work developed within the European Science Foundation Member Organization Forum on 'Indicators for the internationalization'. The authors wish to thank Laura Marin, Elisabeth de Turckheim, and Valerio Vercesi, as well as the participating Funding Agencies. A special thank also to Rémi Barré, for comments to an earlier version, and two anonymous referees for the useful criticisms and suggestions provided.

\section{Notes}

1. A common glossary of the terms used for building indicators was developed as guidelines for dealing with common definitions (e.g., annual budget, researcher, patent, budget appropriation, etc.) and classifications (e.g., fields of science, disciplines, etc.), avoiding misinterpretations or mistakes.

\section{References}

Barré, R. (2004) 'S\&T Indicators for Policy Making in a Changing Science-society Relationship'. In: Moed, H., Glanzel, W. and Schmoch, U. (eds) Handbook of Quantitative Science and Technology Research, pp. 115-32. Dordrecht: Kluwer Academic Publisher. 
- (2010) 'Towards Socially Robust S\&T Indicators: Indicators as Debatable Devices, Enabling Collective Learning', Research Evaluation, 19/3: 227-31.

Boekholt, P., Edler, J., Cunningham, P. and Flanagan, K. (2009) 'Drivers of International Collaboration in Research'. In Report to European Commission, DG Research. Technopolis $B V$, April 2009, Netherlands.

Braun, D. (1998) 'The Role of Funding Agencies in the Cognitive Development of Science', Research Policy, 27: 807-21.

- (2003) 'Lasting Tensions in Research Policy Making-A Delegation Problem', Science and Public Policy, 30/5: 309-21.

Benner, M. and Sandstrom, U. (2000) 'Institutionalizing the Triple Helix: Research Funding and Norms in the Academic System', Research Policy, 29: 291-301.

Bryant, R. (2000) Discovery and Decision. Exploring the Metaphysics and Epistemology of Scientific Classification. London: Associated University Presses.

Caswill, C. (2003) 'Principals, Agents and Contracts', Science and Public Policy, 30/5: 337-46.

CREST Report. (2008) Internationalization of $R \& D$. Brussels: EC.

David, P. and Metcalfe, S. (2007) Universities and Public Research Organisations in the ERA, In Paper for the 8th June 2007 Brussels Meeting of the EC (DG-Research) Expert Group on 'Knowledge and Growth'.

Edler, J. (2010) International Policy Coordination for Collaboration in $S \& T$, Working Paper 590, MBS.

Edler, J. and Flanagan, K. (2011) 'Indicator needs for the Internationalisation of Science Policy', Research Evaluation, 20/1: 7-17.

ERAWATCH. (2009) 'Monitoring Progress Toward the ERA', $<$ http://cordis.europa.eu/erawatch/index.cfm $>$.

—. (2007) 'National Country Reports', <http://www .erawatch.com $>$.

European Commission. (2001) The International Dimension of The European Research Area COM (2001) 346 final, Brussels.

Georghiou, L. (1998) 'Global Cooperation in Research', Research Policy, 27/6: 611-26.

Gornitzka, A., Gulbrandsen, M. and Trondal, J., eds, (2003) Internationalisation of Research and Higher EducationEmerging Patterns of Transformation. Oslo: NIFUNorwegian Institute for Studies in Research and Higher Education.

Godin, B. (2005) Measurement and Statistics on Science and Technology. London: Routledge.
Inzelt, A. (2010) Analysis of Researchers' Mobility in the Context of the European Research Area, (FP7 Evaluation, expert report) <http://ec.europa.eu/research/evalu ations/index_en.cfm?pg $=$ fp7-evidence\&showtoo $=\&$ show $=$ Experts\%20Reports\#Experts\%20Reports $>$.

Kuhlman, S. (2001) 'Future Governance of Innovation Policy in Europe-three Scenarios', Research Policy, 30: 953-76.

Lepori, B. et al. (2007) 'Indicators for Comparative Analysis of Public Project Funding. Concepts, Implementation and Evaluation', Research Evaluation, 16: 243-55.

Lepori, B. (2011) 'Coordination Modes in Public Funding Systems', Research Policy, 40/3: 355-67.

Luukkonen, T. and Nedeva, M. (2010) 'Towards Understanding Integration in Research and Research Policy', Research Policy, 39: 674-86.

Nedeva, M. (2010) 'Toward Developing Indicators for the Evaluation of Research Funding Agencies'. In Paper presented at the 3 ENID Conference on STI Indicators, 3-5 March, Paris.

OECD. (2003) Governance of Public Research. Toward Better Practices. Paris: OECD.

Probst, C., Lepori, B., De Filippo, D. and Ingenhoff, D. (2011) 'Profiles and Beyond: Constructing Consensus on Measuring Research Output in Communication Sciences', Research Evaluation, 201: 73-88.

Skoie, H. (1996) 'Basic Research-A New Funding Climate?', Science and Public Policy, 23/2: 66-75.

Slipersaeter, S., Lepori, B. and Dinges, M. (2007) 'Between Policy and Science: Research Councils' Responsiveness in Austria, Norway and Switzerland', Science and Public Policy, 34/6: 401-15.

Trondal, J. (2002) Why Europeanisation Happens. The Transformative Power of EU Committees, Working paper 3/ 02, ARENA.

Van den Besselaar, P., Inzelt, A. and Reale, E. (2012) 'Measuring Internationalization of Funding Agencies'. In Paper for the 2012 Conference on Science and Technology Indicators (STI 2012), September 2012, Montréal.

Van der Meulen, B. (2003) 'New Roles and Strategies of a Research Council: Intermediation of the Principal-agent Relationship', Science and Public Policy, 30/5: 323-36.

Veugelers, R. et al. (2005) 'Internationalisation of R\&D: Trends, Issues and Implications for S\&T Policy'. In Background Report to the Forum of the Internationalisation of R\&D, 29-30 March 2005, Brussels. 